\title{
Evaluation of brief dietary questions to estimate vegetable and fruit consumption - using serum carotenoids and red-cell folate
}

\author{
Terry Coyne ${ }^{1,2, *}$, Torukiri I lbiebele ${ }^{2}$, Sarah McNaughton ${ }^{1}$, Ingrid HE Rutishauser ${ }^{3}$, \\ Kerin $\mathrm{O}^{\prime} \mathrm{Dea}^{4}$, Allison M Hodge ${ }^{5}$, Christine McClintock ${ }^{2}$, Michael G Findlay ${ }^{2}$ and \\ Amanda Lee ${ }^{\prime}$ \\ ${ }^{1}$ Nutrition Program, School of Population Health, University of Queensland, Brisbane, Queensland, Australia: \\ ${ }^{2}$ Epidemiology Services Unit, Health Information Branch, Queensland Health Building, 147-163 Charlotte Street, \\ Brisbane, Queensland 4001, Australia: ${ }^{3}$ School of Health Sciences, Deakin University, Geelong, Victoria, Australia: \\ ${ }^{4}$ Menzies School of Health Research, Casuarina, Northern Territory, Australia: ${ }^{5}$ Cancer Epidemiology Centre, \\ Cancer Council of Victoria, Carlton, Victoria, Australia: ${ }^{\circ}$ Statewide Health Promotion Unit, Public Health Services, \\ Queensland Health, Brisbane, Queensland, Australia
}

Submitted 26 May 2004: Accepted 13 October 2004

\begin{abstract}
Objective: To evaluate responses to self-administered brief questions regarding consumption of vegetables and fruit by comparison with blood levels of serum carotenoids and red-cell folate.

Design: A cross-sectional study in which participants reported their usual intake of fruit and vegetables in servings per day, and serum levels of five carotenoids ( $\alpha$-carotene, $\beta$-carotene, $\beta$-cryptoxanthin, lutein/zeaxanthin and lycopene) and redcell folate were measured. Serum carotenoid levels were determined by highperformance liquid chromatography, and red-cell folate by an automated immunoassay system.

Settings and subjects: Between October and December 2000, a sample of 1598 adults aged 25 years and over, from six randomly selected urban centres in Queensland, Australia, were examined as part of a national study conducted to determine the prevalence of diabetes and associated cardiovascular risk factors.

Results: Statistically significant $(P<0.01)$ associations with vegetable and fruit intake (categorised into groups: $\leq 1$ serving, $2-3$ servings and $\geq 4$ servings per day) were observed for $\alpha$-carotene, $\beta$-carotene, $\beta$-cryptoxanthin, lutein/zeaxanthin and red-cell folate. The mean level of these carotenoids and of red-cell folate increased with increasing frequency of reported servings of vegetables and fruit, both before and after adjusting for potential confounding factors. A significant association with lycopene was observed only for vegetable intake before adjusting for confounders. Conclusions: These data indicate that brief questions may be a simple and valuable tool for monitoring vegetable and fruit intake in this population.
\end{abstract}

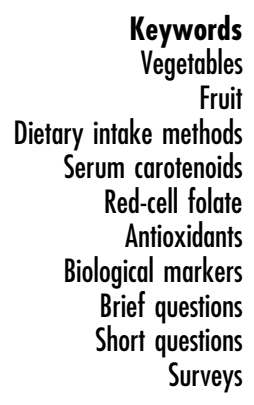

There is convincing evidence that high intakes of vegetables and fruit are associated with lower risk of chronic diseases $^{1-5}$. International ${ }^{1}$ and national health organisations $^{6,7}$ have recommended increasing the consumption of vegetables and fruit as an important health and nutrition priority. Numerous government agencies around the world have instituted health promotion programmes aimed at increasing consumption of vegetables and fruit at the population level ${ }^{8-10}$.

Several methods of monitoring vegetable and fruit consumption are currently being used in various settings. Dietary assessment methods range from detailed weighed food diaries, to 24-hour recalls conducted by trained interviewers, to self-administered food-frequency questionnaires (FFQs) and brief food behaviour checklists.
In Australia, the National CATI Technical Reference Group has recommended several specific dietary questions related to vegetable and fruit consumption for inclusion in CATI (computer-assisted telephone interview) surveys ${ }^{11}$. CATI surveys offer the benefit of using brief questionnaires on a relatively large sample of people. The short dietary questions used in the present study were first used in the 1995 National Nutrition Survey conducted by the Australian Bureau of Statistics ${ }^{12}$ and again in the 2001 National Health Survey ${ }^{13}$ to monitor vegetable and fruit intake of the population. Several studies have evaluated these brief vegetable and fruit intake questions using other dietary assessment methods, such as 3-day weighed food records $^{14}$, 24-hour recalls ${ }^{15}$ or $\mathrm{FFQs}^{16}$, with promising results. However, only a few 'brief' questionnaires 
concerning vegetable and fruit intake have been evaluated using biological measures ${ }^{17-19}$. Biochemical measures have been used to validate increased intake of folate, vitamin $\mathrm{B}_{6}$ and ascorbic acid in an indigenous community $^{20}$. Concentrations of several nutrients in the blood (serum carotenoids, and red-cell folate) are considered reliable markers of vegetable and fruit dietary intake ${ }^{21-28}$.

The purpose of the present study was to evaluate responses to self-administered brief questions regarding consumption of vegetables and fruit in comparison with circulating levels of serum carotenoids and red-cell folate.

\section{Materials and methods}

The study was conducted in Queensland, Australia between October and December 2000, as part of a national study - The Australian Diabetes, Obesity and Lifestyle Study (AusDiab) - to determine the prevalence of diabetes and associated cardiovascular risk factors among adults aged 25 years and over ${ }^{29}$. The International Diabetes Institute and The University of Queensland ethics committees approved the study. Six urban sites were randomly selected from census collector districts in Queensland. Trained interviewers conducted house-tohouse interviews and eligible participants were invited to attend a biomedical and physical examination, which included anthropometric measurements, collection of a blood sample and standardised questionnaires related to sociodemographic and lifestyle- or health-related characteristics. All respondents gave informed consent to participate in the survey upon arrival at the testing site. Details of the sampling framework and overall study design have been published elsewhere ${ }^{30}$. A total of 1634 persons (approximately 30\% of those estimated to be eligible) completed the examination. Complete data for the serum carotenoids, red-cell folate and brief dietary questions were available for 1598 adults.

Brief dietary questions were administered at the testing site. Participants were asked 'How many servings of vegetables do you usually eat each day? including fresh, frozen or tinned vegetables. $A$ serving $=1 / 2$ cup of cooked vegetables or 1 cup of salad vegetables'. Usual daily consumption of fruit was assessed by the question, 'How many servings of fruit do you usually eat each day? including fresh, frozen or tinned fruit. $A$ serving $=1$ medium piece or 2 small pieces of fruit or 1 cup of diced pieces of fruit'. Possible responses were: don't eat vegetables/fruit, eat 1 serving or less, eat 2 to 3 servings, eat 4 to 5 servings, eat 6 servings or more.

Participants were categorised into three groups according to their responses. Although there were five possible response categories, the two extreme categories contained only a very small number of responses while the middle category contained most of the responses. Therefore those reporting don't eat or eat 1 serving or less formed one group, those reporting 2 to 3 servings formed a second group, and those reporting 4 to 5 servings or 6 servings or more formed a third group.

Participants arrived for the study examination having fasted for at least $12 \mathrm{~h}$ and, if not taking hypoglycaemic medication, completed a 2 -h oral glucose tolerance test (OGTT) after consuming a drink containing $75 \mathrm{~g}$ glucose. Blood was drawn for the serum carotenoid and red-cell folate determinations at the time of the 2-h OGTT or $2 \mathrm{~h}$ after the fasting sample for those who did not complete the OGTT. Serum samples for the carotenoid determinations were handled meticulously and protected from light at each stage of processing to prevent deterioration and degradation $^{31}$. The serum was pipetted, frozen, packed in dry ice and shipped to a laboratory in Brisbane for analysis. Serum samples were analysed within 3 weeks of collection. Five serum carotenoids ( $\alpha$-carotene, $\beta$-carotene, $\beta$-cryptoxanthin, lutein/zeaxanthin and lycopene) were assayed simultaneously using the high-performance liquid chromatography procedure described by Talwar et $a$. $^{32}$. Red-cell folate was measured using the Bayer Advia Centuar automated immunoassay system (Bayer, Melbourne, Australia). Lipids (total cholesterol, highdensity lipoprotein (HDL)-cholesterol and triglycerides) were measured enzymatically on an Olympus AU 600. Low-density lipoprotein (LDL)-cholesterol was calculated from the Friedwald formula ${ }^{33}$ :

$$
\begin{aligned}
\mathrm{LDL}-\text { cholesterol }= & \text { total cholesterol }-[\text { HDL-cholesterol } \\
& +(\text { triglycerides } / 5)] .
\end{aligned}
$$

Demographic and other lifestyle variables were collected using standardised questionnaires and were categorised as follows. Age was divided into 10-year age groupings. Educational status was categorised as postgraduate qualification, trade certificate or bachelor's degree, and secondary school or less. Body mass index (BMI) was categorised as underweight $\left(\mathrm{BMI}<20 \mathrm{~kg} \mathrm{~m}^{-2}\right.$ ), normal (BMI $\geq 20$ to $<25 \mathrm{~kg} \mathrm{~m}^{-2}$ ), overweight (BMI $\geq 25$ to $<30 \mathrm{~kg} \mathrm{~m}^{-2}$ ) and obese $\left(\mathrm{BMI} \geq 30 \mathrm{~kg} \mathrm{~m}^{-2}\right.$ ). Smoking status was categorised as never (smoked less than 100 cigarettes during lifetime), former smoker (smoke less than daily for at least the last 3 months, but used to smoke daily) and current smoker (smoke at least daily) ${ }^{29}$. Physical activity beneficial to health was categorised as sufficiently active (greater than $150 \mathrm{~min}$ of 'physical activity time' in the previous week), insufficiently active but not sedentary (less than 150 min of 'physical activity time' in the previous week) and sedentary (no participation in physical activity in the previous week). 'Physical activity time' was calculated as the sum of the time spent walking or performing moderate activity, plus double the time spent in vigorous activity to reflect its greater intensity ${ }^{34}$. Vitamin supplement use during the previous $24 \mathrm{~h}$ was categorised as yes for respondents who indicated that they took any vitamin or mineral supplements on the previous day, and no for respondents who indicated they did not. Alcohol 
consumption was categorised as none, 60 or fewer standard drinks per month or greater than 60 standard drinks per month.

Plasma lipids were categorised using the criteria for abnormal lipid levels based on recommendations by the National Heart Foundation ${ }^{35}$ and the Australian Diabetes Society $^{36}$. Dietary intake of total and saturated fat was estimated using the validated Cancer Council of Victoria FFQ, which is a self-administered, semi-quantitative questionnaire containing 80 food and beverage items with 10 frequency options ranging from never to three or more times a day ${ }^{37}$.

\section{Statistical analyses}

To account for unequal probability of selection and for non-response, data were weighted to the Queensland population for the survey year. The weighted data were analysed using the survey (SVY) commands (for survey data) available in STATA Statistical Software version $8^{38}$. These commands take into account the cluster survey design in the calculation of point estimates, variance and standard errors.

Distributions of serum carotenoids and red-cell folate were skewed and therefore were logarithmically transformed to better approximate normal distribution for regression analyses. Results are expressed as geometric means and proportions. The $t$-test and analysis of variance were used to estimate differences in means between groups. Pearson's chi-square statistic was used to test for significant differences in proportions.

The association between serum carotenoids and red-cell folate versus reported number of servings of vegetables and fruits was estimated by performing multiple regression, in which the log-transformed serum carotenoids and red-cell folate were the outcome variables and reported number of servings of vegetables and fruit were the explanatory variables. Analysis was performed for each serum carotenoid and red-cell folate separately, adjusting for potential confounders. Potential confounders or covariates were those variables identified that were significantly associated with serum carotenoids and redcell folate, as well as vegetable and fruit intake (age, sex and vitamin use), and also variables that were significantly associated with serum carotenoids and red-cell folate only (sex, age, BMI, smoking, vitamin use, alcohol intake, total cholesterol, HDL-cholesterol, LDL-cholesterol and triglycerides). The covariates were included simultaneously into the regression model.

All tests were two-tailed with significance criterion of $P<0.01$. Due to missing values, the sample size was not the same for all variables.

\section{Results}

Table 1 provides the unadjusted geometric mean levels of serum carotenoids and red-cell folate by sociodemographic, anthropometric and health-related behaviour variables, and categories of plasma lipids. Differences between groups were considered significant at $P<0.01$ level.

Mean serum carotenoids (with the exception of lycopene) and red-cell folate levels were significantly lower for males, younger adults, the obese (except red-cell folate), current smokers, those who reported no vitamin or supplement use (except $\beta$-cryptoxanthin, lutein/zeaxanthin) and those who reported consuming more than 60 standard drinks per month (except red-cell folate). Lycopene levels were significantly lower for the elderly, those without tertiary education, obese individuals and those not usually consuming alcohol.

Mean serum carotenoid and red-cell folate levels were significantly lower for those with total cholesterol $<5.5 \mathrm{mmoll}^{-1}$ ( $\beta$-cryptoxanthin and lutein/zeaxanthin only), HDL-cholesterol $<1.0 \mathrm{mmol}^{-1}$ (except lycopene and red-cell folate), LDL-cholesterol $<3.5 \mathrm{mmoll}^{-1}$ (except $\alpha$-carotene and red-cell folate) and those with triglycerides $\geq 2.0 \mathrm{mmoll}^{-1}$ (except $\beta$-cryptoxanthin, lutein/zeaxanthin and red-cell folate). Red-cell folate levels were significantly lower for those with triglyceride levels $<2.0 \mathrm{mmoll}^{-1}$. There was no relationship between any serum carotenoid and total dietary fat and saturated fat at the $P<0.01$ level (data not shown in Table 1 ).

Table 2 provides the distribution of selected categorical variables by vegetable intake. The result indicates that females were more likely than males to report usually consuming 4 or more servings of vegetables, as were those who reported vitamin/supplement use. The proportion of respondents who reported consuming 4 or more servings of vegetables also increased significantly with age.

Table 3 provides the distribution of selected categorical variables by fruit intake. Females were more likely than males to report consuming 4 or more servings of fruit, as were those who did not smoke, those who reported consuming none or fewer than 60 alcoholic drinks per month, those who reported sufficient physical activity and those who reported vitamin/supplement use in the previous $24 \mathrm{~h}$. The proportion of respondents who reported consuming 4 or more servings of fruit also increased significantly with age.

Table 4 provides the unadjusted and adjusted geometric mean levels of serum carotenoids and red-cell folate by vegetable and fruit intake adjusting for potential confounders. The unadjusted geometric means of $\alpha$ carotene, $\beta$-carotene, $\beta$-cryptoxanthin, lutein/zeaxanthin and red-cell folate increased significantly with increasing frequency of vegetable and fruit intake. This association remained after adjusting for the variables associated with the blood nutrient levels as well as vegetable and fruit intakes (adjustment 1: sex, age and vitamin use). The association also remained after adjusting for all the variables associated with serum carotenoids and red-cell folate only (adjustment 2: sex, age, BMI, smoking, vitamin 
Evaluation of brief dietary questions

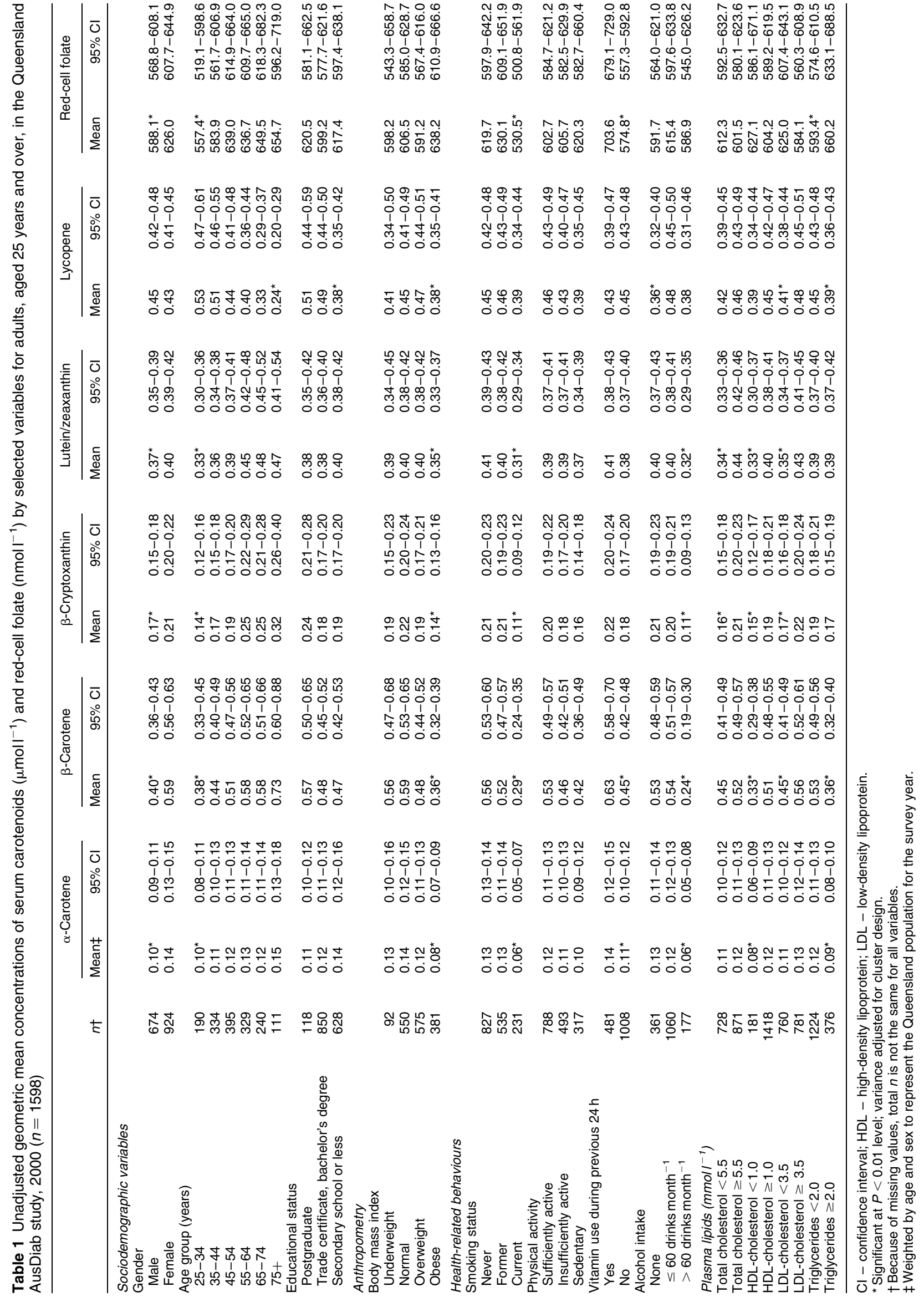


Table 2 Distribution of number of servings of vegetables usually consumed by selected sociodemographic and health variables for adults, aged 25 years and over, in the Queensland AusDiab study, $2000(n=1598)$

\begin{tabular}{|c|c|c|c|c|c|c|c|}
\hline & \multicolumn{6}{|c|}{ Reported number of servings of vegetables usually consumed } & \multirow[b]{3}{*}{$P$-value } \\
\hline & \multicolumn{2}{|c|}{$\leq 1$ serving day ${ }^{-1}$} & \multicolumn{2}{|c|}{$\begin{array}{c}2-3 \\
\text { servings day }^{-1}\end{array}$} & \multicolumn{2}{|c|}{$\begin{array}{c}\geq 4 \\
\text { servings day }^{-1}\end{array}$} & \\
\hline & $n \dagger$ & $\% \neq$ & $n$ & $\%$ & $n$ & $\%$ & \\
\hline \multicolumn{8}{|l|}{ Sociodemographic variables } \\
\hline Gender & & & & & & & 0.0001 \\
\hline Male & 145 & 21.2 & 386 & 59.0 & 137 & 19.8 & \\
\hline Female & 110 & 12.7 & 477 & 52.4 & 343 & 34.9 & \\
\hline Age group (years) & & & & & & & 0.0001 \\
\hline $25-34$ & 43 & 20.8 & 120 & 63.8 & 27 & 15.4 & \\
\hline $35-44$ & 59 & 17.9 & 178 & 54.8 & 90 & 27.3 & \\
\hline $45-54$ & 64 & 16.1 & 208 & 53.1 & 121 & 30.8 & \\
\hline $55-64$ & 37 & 12.6 & 168 & 51.1 & 127 & 36.3 & \\
\hline $65-74$ & 28 & 11.8 & 135 & 55.0 & 82 & 33.2 & \\
\hline $75+$ & 24 & 19.3 & 54 & 47.1 & 33 & 33.6 & \\
\hline Educational status & & & & & & & 0.1621 \\
\hline Postgraduate & 13 & 13.7 & 73 & 63.0 & 31 & 23.3 & \\
\hline Trade certificate, bachelor's degree & 140 & 17.8 & 463 & 56.3 & 241 & 25.9 & \\
\hline Secondary school or less & 99 & 15.7 & 324 & 53.1 & 206 & 31.2 & \\
\hline \multicolumn{8}{|l|}{ Anthropometry } \\
\hline Body mass index & & & & & & & 0.1123 \\
\hline Underweight & 13 & 14.8 & 63 & 68.2 & 23 & 17.0 & \\
\hline Normal & 86 & 17.6 & 286 & 51.6 & 177 & 30.8 & \\
\hline Overweight & 98 & 17.4 & 307 & 56.4 & 167 & 26.2 & \\
\hline Obese & 58 & 15.4 & 207 & 56.5 & 113 & 28.1 & \\
\hline \multicolumn{8}{|l|}{ Health-related behaviours } \\
\hline Smoking status & & & & & & & 0.1353 \\
\hline Never & 116 & 14.7 & 448 & 57.6 & 256 & 27.7 & \\
\hline Former & 87 & 17.1 & 284 & 54.2 & 167 & 28.7 & \\
\hline Current & 51 & 22.6 & 127 & 53.3 & 51 & 24.1 & \\
\hline Physical activity & & & & & & & 0.0501 \\
\hline Sufficient & 105 & 13.8 & 425 & 56.7 & 254 & 29.5 & \\
\hline Insufficiently active & 88 & 19.7 & 267 & 55.4 & 136 & 24.9 & \\
\hline Sedentary & 62 & 20.3 & 171 & 53.0 & 90 & 26.6 & \\
\hline Vitamin use during previous $24 \mathrm{~h}$ & & & & & & & 0.0114 \\
\hline Yes & 61 & 15.1 & 251 & 51.9 & 174 & 33.0 & \\
\hline No & 182 & 17.8 & 573 & 57.6 & 271 & 24.6 & \\
\hline Alcohol intake & & & & & & & 0.4343 \\
\hline None & 57 & 18.3 & 183 & 52.8 & 115 & 28.9 & \\
\hline$\leq 60$ drinks month $^{-1}$ & 160 & 15.6 & 586 & 57.1 & 313 & 27.4 & \\
\hline$>60$ drinks month $^{-1}$ & 37 & 20.9 & 92 & 52.3 & 51 & 26.8 & \\
\hline \multicolumn{8}{|l|}{ Plasma lipids (mmoll $\left.{ }^{-1}\right)$} \\
\hline Total cholesterol $<5.5$ & 117 & 16.6 & 393 & 56.5 & 217 & 26.9 & 0.8068 \\
\hline Total cholesterol $\geq 5.5$ & 138 & 17.1 & 470 & 54.7 & 263 & 28.2 & \\
\hline HDL-cholesterol $<1.0$ & 41 & 23.2 & 95 & 55.7 & 40 & 21.0 & 0.0560 \\
\hline HDL-cholesterol $\geq 1.0$ & 214 & 16.0 & 768 & 55.6 & 440 & 28.4 & \\
\hline LDL-cholesterol < 3.5 & 119 & 16.2 & 405 & 56.0 & 240 & 27.8 & 0.9499 \\
\hline LDL-cholesterol $\geq 3.5$ & 119 & 16.7 & 427 & 55.1 & 231 & 28.2 & \\
\hline Triglycerides $<2.0$ & 187 & 15.9 & 654 & 55.5 & 386 & 28.6 & 0.0979 \\
\hline Triglycerides $\geq 2.0$ & 68 & 20.3 & 209 & 56.0 & 94 & 23.6 & \\
\hline
\end{tabular}

HDL - high-density lipoprotein; LDL - low-density lipoprotein.

*Variance adjusted for cluster design.

† Because of missing values, total $n$ is not the same for all variables.

$\ddagger$ Weighted by age and sex to represent the Queensland population for the survey year.

use, alcohol intake, serum total cholesterol, HDLcholesterol, LDL-cholesterol and triglycerides). Unadjusted geometric means of lycopene increased significantly, but in a non-linear manner, with vegetable intake, but not with fruit intake. After adjustment, the significant association between lycopene and increased frequency of vegetable intake disappeared. Serum lycopene did not show a significant association with frequency of fruit intake either before or after adjustment for potential confounders.

\section{Discussion}

Our data indicate that brief questions related to usual intake of vegetables and fruit may be useful tools for monitoring key dietary behaviours. We found that the 
Table 3 Distribution of number of servings of fruit usually consumed by selected sociodemographic and health variables for adults, aged 25 years and over, in the Queensland AusDiab study, $2000(n=1598)$

\begin{tabular}{|c|c|c|c|c|c|c|c|}
\hline & \multicolumn{6}{|c|}{ Reported number of servings of fruit usually consumed } & \multirow[b]{3}{*}{$P$-value } \\
\hline & \multicolumn{2}{|c|}{$\begin{array}{c}\leq 1 \\
\text { serving day }^{-1}\end{array}$} & \multicolumn{2}{|c|}{$\begin{array}{c}2-3 \\
\text { servings day }^{-1}\end{array}$} & \multicolumn{2}{|c|}{$\begin{array}{c}\geq 4 \\
\text { servings day }^{-1}\end{array}$} & \\
\hline & $n \dagger$ & $\% \ddagger$ & $n$ & $\%$ & $n$ & $\%$ & \\
\hline \multicolumn{8}{|l|}{ Sociodemographic variables } \\
\hline Gender & & & & & & & 0.0003 \\
\hline Male & 312 & 47.5 & 282 & 41.6 & 71 & 10.9 & \\
\hline Female & 320 & 36.6 & 485 & 51.0 & 122 & 12.4 & \\
\hline Age group (years) & & & & & & & 0.0001 \\
\hline $25-34$ & 98 & 52.3 & 76 & 40.2 & 15 & 7.5 & \\
\hline $35-44$ & 165 & 49.0 & 133 & 40.4 & 31 & 10.6 & \\
\hline $45-54$ & 159 & 40.1 & 192 & 48.9 & 42 & 11.0 & \\
\hline $55-64$ & 110 & 33.2 & 170 & 52.0 & 52 & 14.8 & \\
\hline $65-74$ & 70 & 28.0 & 136 & 55.7 & 36 & 16.3 & \\
\hline $75+$ & 30 & 26.6 & 60 & 54.8 & 17 & 18.6 & \\
\hline Educational status & & & & & & & 0.0385 \\
\hline Postgraduate & 35 & 28.5 & 61 & 54.2 & 21 & 17.3 & \\
\hline Trade certificate, bachelor's degree & 338 & 43.5 & 410 & 46.1 & 93 & 10.4 & \\
\hline Secondary school or less & 252 & 41.8 & 295 & 45.5 & 79 & 12.7 & \\
\hline \multicolumn{8}{|l|}{ Anthropometry } \\
\hline Body mass index & & & & & & & 0.1260 \\
\hline Underweight & 52 & 55.5 & 36 & 36.1 & 10 & 8.4 & \\
\hline Normal & 207 & 40.7 & 269 & 46.8 & 70 & 12.5 & \\
\hline Overweight & 227 & 41.6 & 269 & 45.5 & 73 & 12.8 & \\
\hline Obese & 146 & 39.9 & 193 & 50.6 & 40 & 9.5 & \\
\hline \multicolumn{8}{|l|}{ Health-related behaviours } \\
\hline Smoking status & & & & & & & 0.0001 \\
\hline Never & 284 & 36.4 & 421 & 50.0 & 111 & 13.6 & \\
\hline Former & 201 & 40.1 & 269 & 48.7 & 65 & 11.2 & \\
\hline Current & 140 & 60.4 & 77 & 33.6 & 13 & 5.9 & \\
\hline Physical activity & & & & & & & 0.0013 \\
\hline Sufficient & 271 & 37.4 & 390 & 48.1 & 119 & 14.5 & \\
\hline Insufficiently active & 208 & 44.4 & 236 & 46.4 & 46 & 9.2 & \\
\hline Sedentary & 153 & 49.9 & 141 & 41.9 & 28 & 8.2 & \\
\hline \multicolumn{7}{|l|}{ Vitamin use during previous $24 \mathrm{~h}$} & 0.0001 \\
\hline Yes & 170 & 36.2 & 234 & 46.4 & 80 & 17.4 & \\
\hline No & 429 & 44.0 & 494 & 47.1 & 101 & 8.9 & \\
\hline \multicolumn{7}{|l|}{ Alcohol intake } & 0.0041 \\
\hline None & 126 & 37.6 & 178 & 48.8 & 47 & 13.6 & \\
\hline$\leq 60$ drinks month $^{-1}$ & 407 & 40.6 & 522 & 48.1 & 128 & 11.3 & \\
\hline$>60$ drinks month $^{-1}$ & 95 & 55.8 & 67 & 33.5 & 18 & 10.7 & \\
\hline \multicolumn{8}{|l|}{ Plasma lipids $\left(\mathrm{mmol}^{-1}\right)$} \\
\hline Total cholesterol $<5.5$ & 288 & 41.0 & 356 & 48.5 & 79 & 10.5 & 0.2229 \\
\hline Total cholesterol $\geq 5.5$ & 344 & 42.9 & 411 & 44.2 & 114 & 12.9 & \\
\hline HDL-cholesterol $<1.0$ & 85 & 49.6 & 78 & 41.6 & 14 & 8.8 & 0.1432 \\
\hline HDL-cholesterol $\geq 1.0$ & 547 & 40.9 & 689 & 47.0 & 179 & 12.1 & \\
\hline LDL-cholesterol $<3.5$ & 299 & 41.3 & 374 & 47.6 & 88 & 11.1 & 0.4331 \\
\hline LDL-cholesterol $\geq 3.5$ & 303 & 41.9 & 366 & 44.9 & 105 & 13.3 & \\
\hline Triglycerides $<2.0$ & 474 & 41.7 & 591 & 46.4 & 157 & 11.9 & 0.8362 \\
\hline Triglycerides $\geq 2.0$ & 158 & 43.0 & 176 & 46.3 & 36 & 10.7 & \\
\hline
\end{tabular}

HDL - high-density lipoprotein; LDL - low-density lipoprotein.

* Variance adjusted for cluster design.

† Because of missing values, total $n$ is not the same for all variables.

$\ddagger$ Weighted by age and sex to represent the Queensland population for the survey year.

responses to these two relatively simple questions had positive associations with objective markers of vegetable and fruit intake.

Several biological measures, particularly serum carotenoids, have been shown to have good agreement with vegetable and fruit intakes as assessed by more intensive methods of dietary assessment. In a small study using weighed food records, Polsinelli et al. ${ }^{39}$ found moderate correlations between total vegetable and fruit intake in servings per day and $\beta$-carotene, lutein and $\alpha$-carotene ( $r=0.48,0.60$ and 0.73 , respectively). Positive and modest agreement has also been found between individual serum carotenoid levels (except lycopene) and vegetable and fruit intake as assessed by 24-hour recall methods ${ }^{18}$. Researchers have reported moderate correlations between carotenoids and usual intake of vegetables and/or fruit from food frequencies in several countries: Mexico ${ }^{40}$, $\operatorname{Japan}^{41}$, the USA ${ }^{18,19,25,42,43}$ and the $\mathrm{UK}^{44}$. 


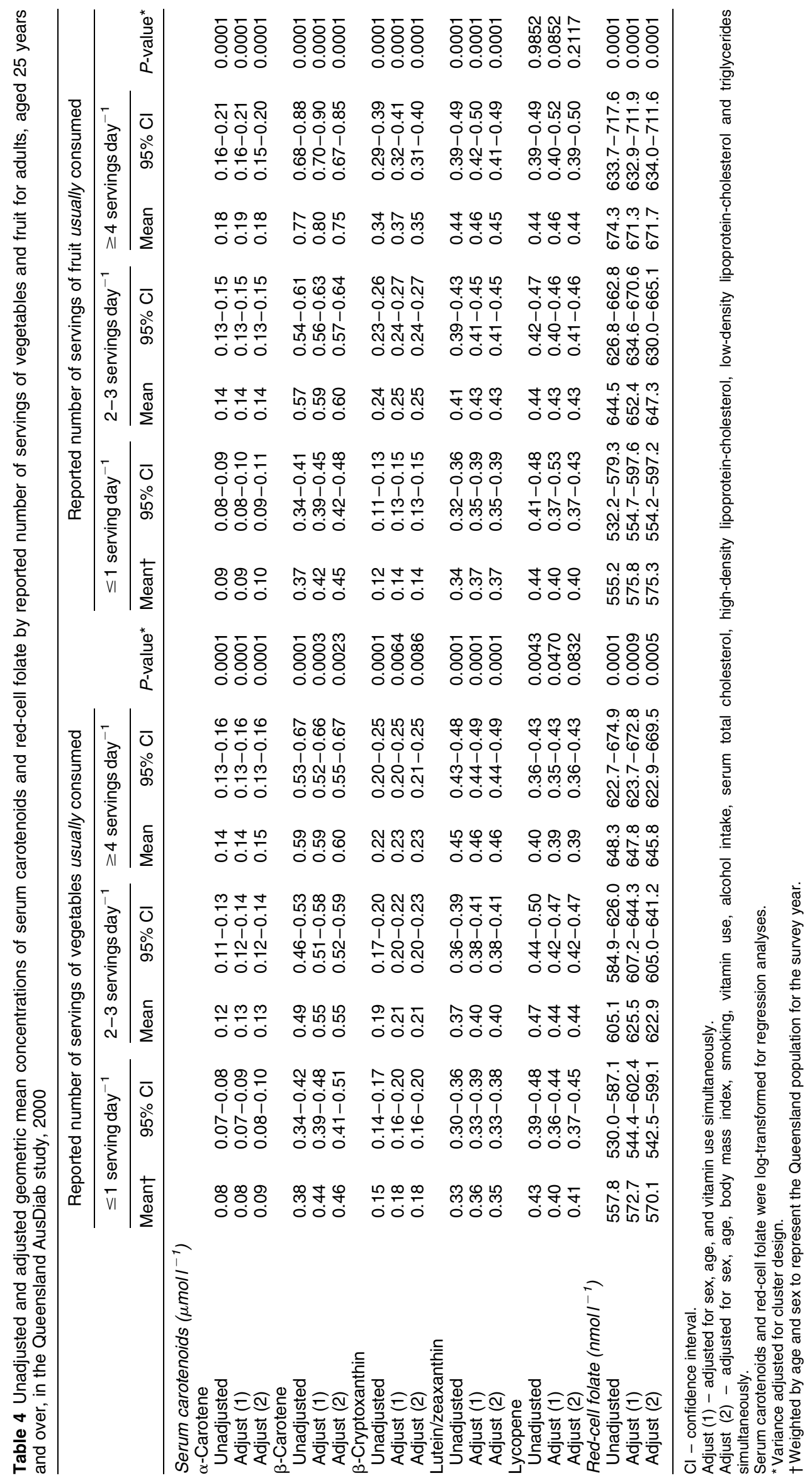


A study by Carroll et $a l^{44}$ found poor correlations (except among younger males) between intake of individual dietary carotenoids estimated from an FFQ and plasma carotenoids. The low correlations in this study may have been due to factors such as incomplete food composition data for individual carotenoids and not controlling for confounding factors, particularly smoking and alcohol intake.

Correlations between fruit intake and serum carotenoids, particularly $\beta$-cryptoxanthin, have been shown to be higher than correlations with serum ascorbic acid ${ }^{27}$. Whether serum carotenoids are better markers of fruit intake is, however, controversial, as Block et al. reported that serum vitamin $\mathrm{C}$ is more strongly correlated with total vegetable and fruit consumption ${ }^{22}$.

While significant associations were shown between most of the carotenoids and vegetable and fruit intake in the current study, these were not found for serum lycopene. This supports previous studies, which have found poor or negative associations between serum lycopene and intake of vegetables and fruit ${ }^{25,39,45}$. A possible reason for this is the differing distribution of food sources for lycopene and differing bioavailability compared with other carotenoids. Lycopene is found predominantly in tomatoes and tomato-based products such as tomato paste, tomato sauce and in mixed dishes containing these ingredients, such as pasta sauces and pizzas ${ }^{46}$. In addition, bioavailability from these mixed dishes may be higher as the heating and homogenisation of tomatoes has been shown to increase the bioavailability of lycopene. Absorption of lycopene is also higher from tomato juice than from raw tomatoes $^{47,48}$. Lycopene is also better absorbed when the tomatoes are consumed together with oil ${ }^{49}$.

Serum carotenoids have been shown in intervention studies to respond to increases in vegetable and fruit intakes. In studies where subjects have been given a test diet or counselled to increase vegetable and fruit intake over the short (3-4 week) and medium term (over 6 months) or longer (12 months), serum carotenoids (other than lycopene) have shown significant increases when compared with control groups ${ }^{21,50,51}$. Serum carotenoids have also been shown to decrease in response to reduced vegetable and fruit intake when subjects are placed on diets low in vegetables and fruit over similar time periods ${ }^{21,52}$.

Several studies have also found good agreement between brief questionnaires of vegetable and fruit intake and nutrient biomarkers. Resnicow et al. ${ }^{18}$ assessed the performance of three different vegetable/fruit FFQs and one or more 24-hour recalls using serum carotenoids among African American adults. Although the two-item vegetable and fruit questionnaire performed less well than more detailed questionnaires or 24-hour recalls, significant positive correlations were found, ranging from $r=0.27$ for cryptoxanthin to $r=0.31$ for $\beta$-carotene. There was no correlation between lycopene and any of the questionnaires or the 24-hour recall methods.
Cappuccio et al. ${ }^{19}$ assessed a two-item vegetable and fruit questionnaire using plasma ascorbic acid, $\beta$-carotene, $\alpha$-tocopherol and $24 \mathrm{~h}$ urine potassium excretion on 271 general practice patients in London. They found a significant positive correlation between total vegetable and fruit intake and urinary potassium excretion $(r=0.23$, $P<0.001$ ), but not with $\beta$-carotene. However, when intakes of vegetable and fruit were analysed separately, fruit intake but not vegetable intake correlated with plasma levels of $\beta$-carotene $(P=0.04)$. Although the simple questionnaire had low sensitivity - only 36\% of those in the upper tertile of reported vegetable and fruit intake ( 5 or more servings per day) also had higher levels of biomarkers, it did have high specificity: low concentrations of biomarkers were observed in $76-83 \%$ of those in the lower two tertiles of reported intake.

While our study showed that short question responses can accurately rank people according to higher or lower intakes of fruit and vegetables when compared with concentrations of red-cell folate, this has not been consistently reported in the literature. In Finland, Silaste et $a l^{53}$ reported that mean concentrations of serum and red-cell folate were low on a diet of 1 serving of vegetables and/or fruit per day, and higher on a diet of at least 7 servings of vegetables, berries and citrus fruit per day. Some other studies have also suggested that a dietary pattern associated with higher intakes of vegetables and fruit, as measured by an FFQ, is associated with higher levels of red-cell folate ${ }^{54}$. Another study from the $\mathrm{UK}^{55}$ investigated the effectiveness of three routes of folate intake (folate from food, from foods fortified with folic acid or given as a supplement) to optimise red-cell folate status. A relationship with red-cell folate was found only between folate from supplements and from folate-fortified foods.

Plasma lipids are important determinants of plasma carotenoids. The present study showed a consistent association between plasma lipid levels and concentrations of serum carotenoids. Plasma $\beta$-carotene has been associated with plasma cholesterol in a number of studies $^{56}$. This association is explained by an understanding of the absorption of $\beta$-carotene, which has been summarised by Nierenberg et al. ${ }^{57}$. When $\beta$-carotene is absorbed intact (rather than cleaved and metabolised to retinol and retinoic acid), it is transported via chylomicrons to the liver. It is then secreted with very low-density lipoprotein (VLDL) into the bloodstream but most $\beta$ carotene in the blood is actually found in LDL, as VLDL is converted to LDL in the blood.

\section{Study strengths and limitations}

Our study was conducted on a large sample of adults, both females and males, across a range of ages. Because the study was part of a large diabetes and cardiovascular risk factor study, extensive demographic and other biomedical variables were also collected and could be assessed as potential confounding factors. The brief 
questions related to vegetable and fruit consumption were compared with objective biological markers of diet which are independent of memory, subject compliance and respondent bias ${ }^{58}$. Because the errors associated with the use of biological markers of diet are independent of those associated with questionnaire or recall methods of dietary assessment, the association between diet and these markers is unlikely to be due to correlated errors ${ }^{59}$.

The biological indicators measured in this study were based on a single blood sample. Some studies using biological markers have used multiple blood samples collected at different time points to better characterise an individual's nutrient status ${ }^{59}$. However, Van Kappel et al. ${ }^{24}$, who conducted a longer-term study to investigate the reproducibility of serum levels of carotenoids, found that a single sample could accurately rank individuals for $\alpha$-carotene, $\beta$-carotene and lutein.

The blood samples in the current study were collected after an overnight fast, and are thus unlikely to be affected by carotenoid or red-cell folate intake at the previous meal. Studies have shown that while plasma levels of $\alpha$ - and $\beta$-carotene are altered within a few hours following a carotene-rich meal ${ }^{60}$, a single dose of $\beta$-carotene does not result in continuously raised $\beta$-carotene concentrations 5 or 10 days later. Thus, apart from an initial rise following a meal, carotenoid levels reflect the long-term intake ${ }^{61}$. Red-cell folate also is considered to represent folate status over a longer term, perhaps months ${ }^{62}$.

While our study, along with others, have found moderate correlations between plasma carotenoids and reported usual intake of total vegetables and total fruit, other studies have found stronger associations between specific vegetables and specific fruit intakes and individual carotenoids. For example, Michaud et al. ${ }^{43}$ showed that intake of carrots measured by FFQ was a strong predictor of plasma $\alpha$ - and $\beta$-carotene levels in plasma, while oranges and orange juice intakes predicted plasma $\beta$-cryptoxanthin, and plasma lutein was predicted by lettuce and spinach intakes. Other studies have shown higher correlations between calculated intakes of individual carotenoids and plasma concentration, compared with correlations with total vegetable and fruit intakes ${ }^{42,43}$. While circulating levels of carotenoids may be more strongly correlated with intakes of specific vegetables and fruit, and intakes of individual carotenoids, they are still appropriate as independent estimates of vegetable and fruit intakes for evaluating the brief questions.

\section{Conclusion}

Questions similar to those evaluated in the present study are currently used widely in Australia and other countries in a variety of surveys and settings as a cost-effective way to monitor vegetable and fruit consumption at a population level. While biomarkers do not provide accurate point estimates of vegetable and fruit consumption, they provide an independent means of ranking intakes, against which short questions on fruit and vegetable intake can be compared. By comparison with biomarkers, the short questions evaluated here appear to rank individuals reasonably well. These results provide credibility for the continued widespread use of these brief questions in a variety of population-based surveys and settings to monitor trends in vegetable and fruit consumption.

\section{Acknowledgements}

The national AusDiab study was conducted by the International Diabetes Institute with partial funding from the Commonwealth Department of Health and Aged Care, State and Territory governments and pharmaceutical companies (Eli Lilly (Aust) Pty Ltd, Janssen-Cilag (Aust) Pty Ltd, Knoll Australia Pty Ltd, Merck Lipha SA, Alphapharm Pty Ltd, Merck Sharp \& Dohme (Aust), Pharmacia and Upjohn Pty Ltd, Roche Diagnostics, Servier Laboratories (Aust) Pty Ltd, SmithKline Beecham International, BioRad Laboratories Pty Ltd, HITECH Pathology Pty Ltd), Qantas Airways Ltd and the Australian Kidney Foundation. The Queensland phase of the study was partially funded by units within Queensland Health (Public Health Services, the Health Information Centre, the Health Service Districts of Cairns, Gold Coast, Prince Charles Hospital, Sunshine Coast, Royal Brisbane Hospital and Toowoomba Health Districts) and the Chemical Pathology Laboratory at Princess Alexandra Hospital.

\section{References}

1 World Health Organization (WHO)/Food and Agriculture Organization. Diet, nutrition and the prevention of chronic diseases: report of a joint WHO/FAO expert consultation. In: Joint WHO/FAO Expert Consultation on Diet, Nutrition and the Prevention of Chronic Diseases. Geneva: WHO, 2002.

2 World Cancer Research Fund (WCRF)/American Institute for Cancer Research (AICR). Vegetables and fruit. In: Food, Nutrition and the Prevention of Cancer: A Global Perspective. Washington, DC: WCRF/AICR, 2000; 436-44.

3 Ness AR, Powles JW. Fruit and vegetables, and cardiovascular disease: a review. International Journal of Epidemiology 1997; 26: 1-13.

4 Liu S, Manson JE, Lee IM, Cole SR, Hennekens CH, Willett WC, et al. Fruit and vegetable intake and risk of cardiovascular disease: the Women's Health Study. American Journal of Clinical Nutrition 2000; 72: 922-8.

5 Sargeant L, Khaw K, Bingham S, Day N, Luben R, Oakes S, et al. Fruit and vegetable intake and population glycosylated haemoglobin levels: the EPIC-NORFOLK study. European Journal of Clinical Nutrition 2001; 55: 342-8.

6 National Health and Medical Research Council (NH\&MRC). Dietary Guidelines for Australians. Canberra: NH\&MRC, 2002.

7 US Department of Health and Human Services (DHHS). Healthy People 2000: National Health Promotion and Disease Prevention Objectives. Washington, DC: US DHHS, 1991. 
8 Strategic Intergovernmental Nutrition Alliance. Eat Well Australia: An Agenda for Action for Public Health Nutrition 2001-2010. Canberra: National Public Health Partnership, 2001.

9 Produce for Better Health Foundation/National Cancer Institute. 5 A Day for Better Health: Guidebook. Newark, DE: Produce for Better Health Foundation/National Cancer Institute, 1991.

10 Department of Health. 5 A DAY Program. Available at: www.doh.gov.uk/fiveaday.

11 CATI Technical Reference Group. SNAP(S) Smoking, Nutrition, Alcohol misuse, Physical inactivity, (Stress). Adelaide: CATI Technical Reference Group, 2001.

12 Australian Bureau of Statistics (ABS). National Nutrition Survey: Selected Highlights, Australia. Catalogue No. 4802.0. Canberra: ABS, 1995.

13 Australian Bureau of Statistics (ABS). National Health Survey: Summary of Results, Australia. Catalogue No. 4364.0. Canberra: ABS, 2001.

14 Riley M, Rutishauser I, Webb K. Comparison of Short Questions with Weighed Food Records. Canberra: Commonwealth Department of Health and Aged Care, 2001.

15 Marks G, Webb K, Rutishauser I, Riley M. Monitoring Food Habits in the Australian Population using Short Questions. Canberra: Commonwealth Department of Health and Aged Care, 2001.

16 Serdula M, Coates R, Byers T, Mokdad A, Jewell S, Chavez N. Evaluation of a brief telephone questionnaire to estimate fruit and vegetable consumption in diverse study populations. Epidemiology 1993; 4: 455-63.

17 Murphy SP, Kaiser LL, Townsend MS, Allen LH. Evaluation of validity of items for a food behaviour checklist. Journal of the American Dietetic Association 2001; 101: 751-61.

18 Resnicow K, Odom E, Wang T, Dudley WN, Mitchell D, Vaughan $\mathrm{R}$, et al. Validation of three food frequency questionnaires and 24-hour recalls with serum carotenoid levels in a sample of African-American adults. American Journal of Epidemiology 2000; 152: 1072-80.

19 Cappuccio F, Rink E, Perkins-Porras L, McKay C, Steptoe A. Estimation of fruit and vegetable intake using a two-item dietary questionnaire: a potential tool for primary health care workers. Nutrition, Metabolism, and Cardiovascular Diseases 2003; 13: 12-9.

20 Lee AJ, Bailey APV, Yarmirr D, O'Dea K, Mathews JD. Survival tucker: improved diet and health indicators in an Aboriginal community. Australian Journal of Public Health 1994; 18: 277-85.

21 Broekmans WM, Klopping-Ketelaars IA, Schuurman CR, Verhagen H, Van den Berg H, Kok FJ, et al. Fruits and vegetables increase plasma carotenoids and vitamins and decrease homocysteine in humans. Journal of Nutrition 2000; 130: 1578-83.

22 Block G, Norkus E, Hudes M, Mandel S, Helzlsouer K. Which plasma antioxidants are most related to fruit and vegetable consumption? American Journal of Epidemiology 2001; 154: $1113-8$.

23 Martini MC, Campbell DR, Gross MD, Grandits GA, Potter JA, Slavin JL. Plasma carotenoids as biomarkers of vegetable intake: The University of Minnesota Cancer Prevention Research Unit feeding studies. Cancer Epidemiology, Biomarkers \& Prevention 1995; 4: 491-6.

24 Van Kappel AL, Steghens JP, Zeleniuch-Jacquotte A, Chajes V, Toniolo P, Riboli E. Serum carotenoids as biomarkers of fruit and vegetable consumption in the New York Women's Health Study. Public Health Nutrition 2001; 4: 829-35.

25 Campbell DR, Gross MD, Martini MC, Grandits GA, Slavin JL, Potter JD. Plasma carotenoids as biomarkers of vegetable and fruit intake. Cancer Epidemiology, Biomarkers $\mathcal{E}$ Prevention 1994; 3: 493-500.
26 Forman MR, Lanza E, Yong LC, Holden JM, Graubard BI, Beecher GR, et al. The correlation between two dietary assessments of carotenoid intake and plasma carotenoid concentrations: application of a carotenoid food-composition database. American Journal of Clinical Nutrition 1993; 58: 519-24.

27 Drewnowski A, Rock CL, Henderson SA, Shore AB, Fischler $\mathrm{C}$, Galan $\mathrm{P}$, et al. Serum $\beta$-carotene and vitamin $\mathrm{C}$ as biomarkers of vegetable and fruit intakes in a communitybased sample of French adults. American Journal of Clinical Nutrition 1997; 65: 1796-802.

28 Ford ES, Bowman BA. Serum and red blood cell folate concentrations, race, and education: findings from the Third National Health and Nutrition Examination Survey. American Journal of Clinical Nutrition 1999; 69: 476-81.

29 Dunstan D, Zimmet P, Welborn T, Sicree R, Armstrong T, Atkins R, et al. Diabesity and Associated Disorders in Australia - 2000. The Accelerating Epidemic. The Australian Diabetes, Obesity and Lifestyle Study (AusDiab). Melbourne: International Diabetes Institute, 2001.

30 Dunstan DW, Zimmet PZ, Welborn TA, Cameron AJ, Shaw J, de Courten M, et al. The Australian Diabetes, Obesity and Lifestyle Study (AusDiab) - methods and response rates. Diabetes Research and Clinical Practice 2002; 57: 119-29.

31 Su Q, Rowley KG, O'Dea K. Stability of individual carotenoids, retinol and tocopherols in human plasma during exposure to light and after extraction. Journal of Chromatography. B, Biomedical Sciences and Applications 1999; 729: 191-8.

32 Talwar D, Ha TK, Cooney J, Brownlee C, O'Reilly DS. A routine method for the simultaneous measurement of retinol, $\alpha$-tocopherol and five carotenoids in human plasma by reverse phase HPLC. Clinica Chimica Acta 1998; 270: $85-100$.

33 Friedwald WT, Levy RJ, Fredrickson DS. Estimation of the concentration of low-density lipoprotein cholesterol in plasma without use of the preparative ultracentrifuge. Clinical Chemistry 1972; 18: 499-502.

34 Armstrong T, Bauman A, Davies J. Physical Activity Patterns of Australian Adults. Result of the 1999 National Physical Activity Survey. Canberra: Australian Institute of Health and Welfare, 2000.

35 National Heart Foundation/Australia Institute of Health. Risk Factor Prevalence Study No. 3 1989. Canberra: National Heart Foundation/Australia Institute of Health, 1990.

36 Australia Diabetes Society. Diabetic dyslipidemia - Australian Diabetes Society position statement. Medical Journal of Australia 1995; 162: 91-3.

37 Hodge A, Patterson AJ, Brown WJ, Ireland P, Giles G. The Anti Cancer Council of Victoria FFQ: relative validity of nutrient intakes compared with weighted food records in young to middle-aged women in a study of iron supplementation. Australian and New Zealand Journal of Public Health 2000; 24: 576-83.

38 StataCorp. Stata Statistical Software: Release 8.0. College Station, TX: Stata Corporation, 2001.

39 Polsinelli ML, Rock CL, Henderson SA, Drewnowski A. Plasma carotenoids as biomarkers of fruit and vegetable servings in women. Journal of the American Dietetic Association 1998; 98: 194-6.

40 Romieu I, Parra S, Hernandez JF, Madrigal H, Willett W, Hernandez M. Questionnaire assessment of antioxidants and retinol intakes in Mexican women. Archives of Medical Research 1999; 30: 224-39.

41 Sasaki S, Ushio F, Amano K, Morihara M, Todoriki T, Uehara $\mathrm{Y}$, et al. Serum biomarker-based validation of a selfadministered diet history questionnaire for Japanese subjects. Journal of Nutritional Science and Vitaminology 2000; 46: 285-96.

42 Tucker KL, Chen H, Vogel S, Wilson PW, Schaefer EJ, 
Lammi-Keefe CJ. Carotenoid intakes, assessed by dietary questionnaire, are associated with plasma carotenoid concentrations in an elderly population. Journal of Nutrition 1999; 129: 438-45.

43 Michaud DS, Giovannucci EL, Ascherio A, Rimm EB, Forman MR, Sampson L, et al. Associations of plasma carotenoid concentrations and dietary intake of specific carotenoids in samples of two prospective cohort studies using a new carotenoid database. Cancer Epidemiology, Biomarkers \& Prevention 1998; 7: 283-90.

44 Carroll YL, Corridan BM, Morrissey PA. Carotenoids in young and elderly healthy humans: dietary intakes, biochemical status and diet-plasma relationships. European Journal of Clinical Nutrition 1999; 53: 644-53.

45 Bodgers R, Dagnelie P, Westerterp KR, Kester A, van Klaveren J, Bast A, et al. Using a correction factor to correct for over-reporting in a food frequency questionnaire does not improve biomarker-assessed validity for estimates for fruit and vegetable consumption. Journal of Nutrition 2003 133: 1213-9.

46 US Department of Agriculture. USDA-NCC Carotenoid Database for US Foods [online], 1998. Available at: http:// www.nal.usda.gov/fnic/foodcomp/Data/car98/car98.html

47 Bohm V, Bitsch R. Intestinal absorption of lycopene from different matrices and interactions to other carotenoids, the lipid status, and the antioxidant capacity of human plasma. European Journal of Nutrition 1999; 38 $118-25$.

48 van het Hof KH, de Boer BC, Tijburg LB, Lucius BR, Zijp I, West CE, et al. Carotenoid bioavailability in humans from tomatoes processed in different ways determined from the carotenoid response in the triglyceride-rich lipoprotein fraction of plasma after a single consumption and in plasma after four days of consumption. Journal of Nutrition 2000; 130: 1189-96.

49 Brown MJ, Ferruzzi MG, Nguyen ML, Cooper DA, Eldridge AL, Schwartz SJ, et al. Carotenoid bioavailability is higher from salads ingested with full-fat than with reduced-fat dressing as measured by electrochemical detection. American Journal of Clinical Nutrition 2004; 80: 396-403.

50 McEligot AJ, Rock CL, Flatt SW, Newman V, Faerber S, Pierce JP. Plasma carotenoids are biomarkers of long-term high vegetable intake in women with breast cancer. Journal of Nutrition 1999; 129: 2258-63.

51 Bernstein A, Nelson ME, Tucker KL, Layne J, Johnson E, Nuernberger A, et al. A home-based nutrition intervention to increase consumption of fruits, vegetables, and calcium-rich foods in community dwelling elders. Journal of the American Dietetic Association 2002; 102: 1421-7.

52 Freese R, Alfthan G, Jauhiainen M, Basu S, Erlund I, Salminen I, et al. High intakes of vegetables, berries, and apples combined with a high intake of linoleic or oleic acid only slightly affect markers of lipid peroxidation and lipoprotein metabolism in healthy subjects. American Journal of Clinical Nutrition 2002; 76: 950-60.

53 Silaste M, Rantala M, Alfthan G, Aro A, Kesaniemi Y. Plasma homocysteine concentration is decreased by dietary intervention. British Journal of Nutrition 2003; 89: 295-301.

54 Kerver JM, Yang EJ, Bianchi L, Song W. Dietary patterns associated with risk factors for cardiovascular disease in healthy US adults. American Journal of Clinical Nutrition 2003; 78: 1103-10.

55 Cuskelly GJ, McNulty H, Scott JM. Effect of increasing dietary folate on red-cell folate: implications for prevention of neural tube defects. Lancet 1996; 347: 657-9.

56 Jarvinen R, Knekt P, Seppanen R, Heinonen M, Aaran RK. Dietary determinants of serum $\beta$-carotene and serum retinol. European Journal of Nutrition 1993; 47: 31-41.

57 Nierenberg DW, Stukel TA, Baron JA, Dain BJ, Greenberg ER Determinants of plasma levels of $\beta$-carotene and retinol. Skin Cancer Prevention Study Group. American Journal of Epidemiology 1989; 130: 511-21.

58 Kaaks R, Riboli E, Sinha R, eds. Biochemical Markers of Dietary Intake. Lyon: International Agency for Research on Cancer Scientific Publications, 1997.

59 Ocke MC, Kaaks R. Biochemical markers as additional measurements in dietary validity studies: application of the method of triads with examples from the European Prospective Investigation into Cancer and Nutrition. American Journal of Clinical Nutrition 1997; 65 $1240 \mathrm{~S}-5 \mathrm{~S}$

60 Jensen C, Spiller G. Acute effects of dietary carotenes on serum $\alpha$ and $\beta$-carotene in humans. Nutrition Reports International 1986; 33: 117s-22s.

61 Johnson E, Suter P, Sahyoun N, Ribaya-Mercado JD, Russell RM. Relation between $\beta$-carotene intake and plasma and adipose tissue concentrations of carotenoids and retinoids. American Journal of Clinical Nutrition 1995; 62 598-603.

62 Gibson RS. Principles of Nutritional Assessment. New York: Oxford University Press, 1990. 